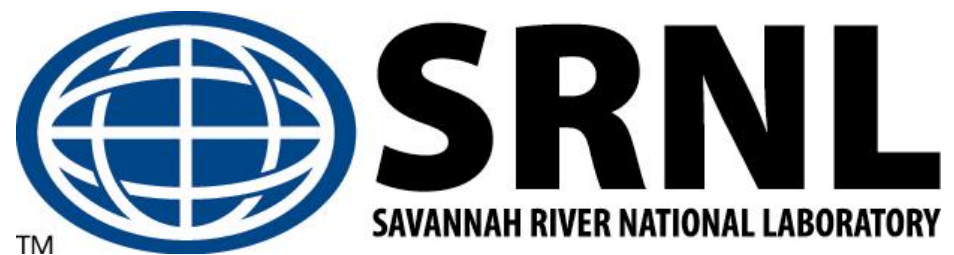

SRNL-STI-2011-00348

\title{
Effect of Filter Temperature on Trapping Zinc Vapor
}

\author{
Paul Korinko
}

March 25, 2011

\section{Savannah River National Laboratory Savannah River Nuclear Solutions Savannah River Site Aiken, South Carolina}

This document was prepared in connection with work done under Contract No. DE-AC09-08SR22470 with the U.S. Department of Energy. By acceptance of this document, the publisher and/or recipient acknowledges the U.S. Government's right to retain a nonexclusive, royalty-free license in and to any copyright covering this document, along with the right to reproduce and authorize others to reproduce all or part of the copyrighted material. 


\section{SRNL-STI-2011-00348}

\section{Effect of Filter Temperature on Trapping Zinc Vapor}

\section{Table of Contents}

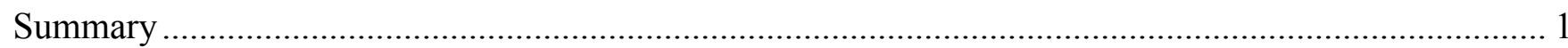

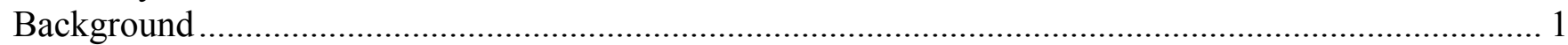

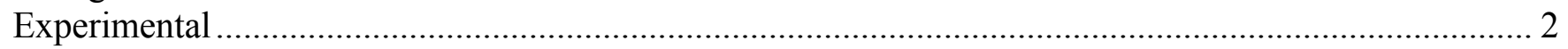

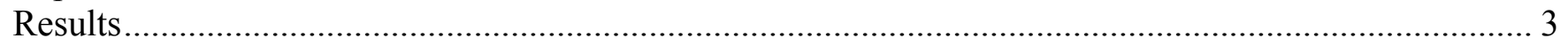

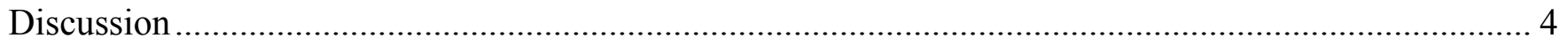

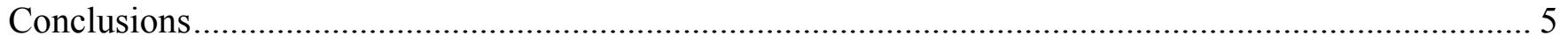

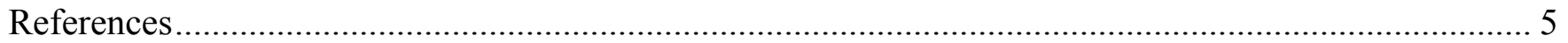

\section{List of Tables}

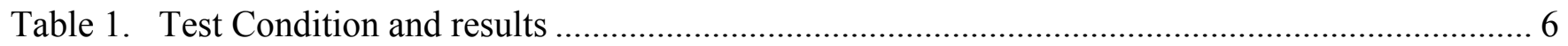

Table 2. Test temperatures and homologous temperature $\left(\mathrm{T}(\mathrm{K}) / \mathrm{T}_{\text {melt }}(\mathrm{K})\right)$, where $\mathrm{T}_{\text {melt }}=419.5^{\circ} \mathrm{C}$ or

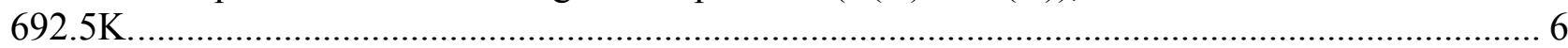

\section{List of Figures}

Figure 1. Photographs of zinc TVD apparatus used for this study .................................................... 7

Figure 2. Pictorial description of the Adhesion Test for a $60^{\circ} \mathrm{C}$ filter test. ............................................ 8

Figure 3. Typical thermal data for the vessel and filter. These data are for a sample exposed at a nominal $400^{\circ} \mathrm{C}$ vessel temperature and a $120^{\circ} \mathrm{C}$ filter temperature............................................ 9

Figure 4. Deposit appearance for filters exposed at $60^{\circ} \mathrm{C}, 120^{\circ} \mathrm{C}$, and $200^{\circ} \mathrm{C}$ in the as deposited (upper) and adhesion tested (lower) conditions. Note: about half the deposit was removed from the $60^{\circ} \mathrm{C}$ sample. This result was consistent across all three $60^{\circ} \mathrm{C}$ filter tests.............................................. 10

Figure 5. Particle and nominal chemistry for the filter exposed at $60^{\circ} \mathrm{C}$. The beam sampling volume included some of the stainless steel filter media............................................................................. 11

Figure 6. Typical deposit found on a filter exposed at $200^{\circ} \mathrm{C}$. EXDA indicates nearly pure zinc......... 12 Figure 7. SEM images from the $60^{\circ} \mathrm{C}$ filter -4 (a) edge low magnification (b) edge high magnification showing flake like structure (c) middle section between edge and center at low magnification (d) higher magnification of (c) (e) center at low magnification and (f) center at high magnification showing flake-like deposit (g) area from the adhesion test demonstrating that surface deposits were removed but not subsurface.

Figure 8. SEM images from the $120^{\circ} \mathrm{C}$ filter -4 (a) edge low magnification (b) edge high magnification showing a flake and the string-like lacy structure (c) middle section between edge and center at low magnification showing little indication of the deposit (d) higher magnification of a particle in (c) (e) center at low magnification and (f) center at high magnification showing a significant lacy deposit $(\mathrm{g})$ area from the adhesion test demonstrating that surface deposits were removed but not subsurface. 
Figure 9. SEM images from the $200^{\circ} \mathrm{C}$ filter -4 (a) edge low magnification (b) edge high magnification showing string like structure (c) middle section between edge and center at low magnification (d) higher magnification of (c) (e) center at low magnification and (f) center at high magnification showing a mixed deposit and (g) lacy/string like deposit in the area from the adhesion test demonstrating that surface deposits were removed but not subsurface.

Figure 10. Typical morphology and $\mathrm{x}$-ray dot maps from the edge sample showing the dispersion of zinc in the sample.

Figure 11. Morphology and X-ray dot maps from the middle of the sample showing the zinc dispersion

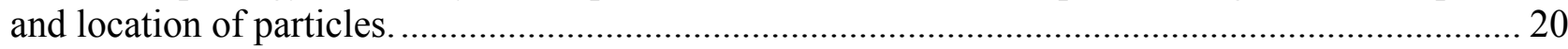

Figure 12. Morphology and X-ray dot maps from the middle of the sample showing the zinc dispersion and location of particles. 21

Figure 13. Morphology and X-ray dot maps from the area below the tape adhesion test near the center of the sample showing the zinc dispersion and location of particles. 


\section{Effect of Filter Temperature on Trapping Zinc Vapor}

\section{Summary}

To address the ${ }^{65} \mathrm{Zn}$ contamination issue in the TEF, a multi-task experimental program was initiated. The first experimental task was completed and is reported in Ref. 1. The results of the second experimental task are reported here. This task examined the effect of filter temperature on trapping efficiency and deposit morphology. Based on the first experimental tasks that examined filter pore size and trapping efficiency, stainless steel filter media with a $20 \mu \mathrm{m}$ pore size was selected. A series of experiments using these filters was conducted during this second task to determine the effect of filter temperature on zinc vapor trapping efficiency, adhesion and morphology. The tests were conducted with the filters heated to 60,120 , and $200^{\circ} \mathrm{C}$; the zinc source material was heated to $400^{\circ} \mathrm{C}$ for all the experiments to provide a consistent zinc source. The samples were evaluated for mass change, deposit adhesion and morphology. As expected from the physical vapor deposition literature, a difference in deposit morphology and appearance was observed between the three filter temperatures. The filter held at $60^{\circ} \mathrm{C}$ had the largest average mass gain while the 120 and $200^{\circ} \mathrm{C}$ filters exhibited similar but lower weight gains. The standard deviations were large and suggest that all three temperatures exhibited comparable gains. No zinc was detected on the backside surface of the filters indicating high efficiency for front and internal trapping. A zinc rich deposit was formed on the surface of the $60^{\circ} \mathrm{C}$ filter. Based on a simple tape adhesion test, the surface zinc was readily removed from the $60^{\circ} \mathrm{C}$ filter while less zinc deposit was removed from the 120 and $200^{\circ} \mathrm{C}$ filter samples. It is surmised that the higher temperatures enable the zinc to deposit within the filter media rather than on the surface. Based on the findings that all three statistically trapped the same quantity of zinc vapor and that the higher temperatures resulted in a more adherent / better trapped product, operating the filters at 120 to $200^{\circ} \mathrm{C}$ is recommended.

\section{Background}

An experimental program was initiated in order to develop and validate conditions that will effectively trap $\mathrm{Zn}$ vapors that are released during extraction. The proposed work was divided into three experimental tasks. The first task was to determine the effectiveness of various pore sizes of filter elements. The second task is to determine the effect of filter temperature on zinc vapor deposition. The final task will be to determine whether the zinc vapors can be chemically bound. The approach for chemically binding the zinc vapors has two subtasks, the first is a review of literature and thermodynamic calculations and the second is an experimental approach using the best candidates. This report details the results of experimental testing to determine the effects of filter temperature on zinc vapor capture (2).

It is known that radioactive zinc $65\left({ }^{65} \mathrm{Zn}\right)$ is extracted from the irradiated TPBARs. Review of the potential sources of ${ }^{65} \mathrm{Zn}$ from the TPBAR sub-elements indicates that it is an activation product of natural zinc and that it is present as a low level contaminant in several of the TPBAR materials $(3,4, \&$ 5). The amounts that are extracted are small but are easily detected due to the gamma radiation that they produce. 
A previous task was conducted to determine the morphology of the zinc deposit and a recommendation was made as to temperature and material (6). Based on this recommendation and the availability of materials, $20 \mu \mathrm{m}$ filters heated to $200^{\circ} \mathrm{C}$ were installed in key areas of the TEF process lines. The postmortem examination of the filters, especially gamma scans, indicated that ${ }^{65} \mathrm{Zn}$ had been trapped within these locations, although the deposit morphology was difficult to characterize due to the presence of native $\mathrm{Zn}$ on the filters (7).

In this study, standard $20 \mu \mathrm{m}$ pore filter disks were used and held at three temperatures. The filters were examined for weight change, deposit adhesion, and deposit morphology.

\section{Experimental}

Mott filter sample coupons $70 \mathrm{~mm}$ in diameter with a pore diameter of $20 \mu \mathrm{m}$ were procured for this study. These filters were used to determine the effect of filter temperature on deposit efficiency, adhesion, and morphology. The filters were weighed on a five place Sartorius analytical balance and a four place Denver Instruments analytical balance before and after exposure to determine the amount of zinc deposited.

The shorter thermal vapor deposition (TVD) vessel (Ref. 1) was used for this experiment, using the same Mott filter element holder, Fig. 1; this apparatus was also used for the pore size evaluation task. The system was evacuated to a pressure of nominally $5 \times 10^{-2}$ Torr using a scroll pump, and pumping for at least two hours prior to heating the filter and vessel heating mantles. The data were logged using Labview software and vendor software. The filter heater was programmed to heat to the set point at a nominal heating rate of $10^{\circ} \mathrm{C} / \mathrm{min}$ and was held for four to five hours so the filter was at the desired temperature for the entire time that the zinc vessel was above $300^{\circ} \mathrm{C}$, which is the temperature at which the zinc vapor pressure becomes significant. The vessel, for all of the experiments, was heated to a setpoint of $400^{\circ} \mathrm{C}$ also at a rate of $10^{\circ} \mathrm{C} / \mathrm{min}$ and was held for 3 hours. The zinc source reached a temperature of nominally $350^{\circ} \mathrm{C}$.

The adhesion of the deposit to the filter media was tested using yellow warning tape, and the same roll of tape was used for all of the tests. The samples were weighed, tape was applied to one half of the sample, the tape was removed and the sample reweighed. In addition, the tape was visually examined after removal. The test sequence is shown in Fig. 2.

The deposit morphology on the half of the sample that was not adhesion tested was characterized using scanning electron microscopy (SEM). The samples were taped to the SEM stubs and examined at about $1 / 4$ " from the edge, midway between the center of the sample and the first point and at the center. The chemical make-up of the particles was determined using X-ray energy dispersive spectroscopy (XEDA). $\mathrm{X}$-ray dot mapping was used to select areas of interest for higher magnification examination. Accelerating voltages of 5 and $10 \mathrm{kV}$ were used; $5 \mathrm{kV}$ was used for the $\mathrm{x}$-ray analysis and some imaging and $10 \mathrm{kV}$ was used for selective imaging. 


\section{Results}

A typical data plot for the vessel heated to $400^{\circ} \mathrm{C}$ and the filter heated to $120^{\circ} \mathrm{C}$ is shown in Figure 3 . These data show the initial time lag of 2 hours for evacuation prior to heating the filter or vessel. The onset of zinc vaporization is indicated by the spike in pressure. This pressure increase corresponds to a an internal temperature of approximately $300^{\circ} \mathrm{C}$. The pressure decreases initially on further heating but eventually increases and holds constant at nearly 1 Torr until the vessel is cooled. The filter housing was intended to maintain the desired temperature for the entire time that the internal vessel temperature was above $300^{\circ} \mathrm{C}$. In general, this goal was achieved.

The weight gain data for each test is listed in Table 1. Of note is the fact that two of the three data for the $60^{\circ} \mathrm{C}$ exhibit gains in excess of $3.5 \mathrm{mg}$ while the 120 and $200^{\circ} \mathrm{C}$ exhibit gains of about $2.5 \mathrm{mg}$. The average weight gain and standard deviations for the gains are shown in Table 2. These data suggest that despite the large individual values, all three temperatures exhibited comparable weight gains on average and within the scatter.

Based on visual examination, it is interesting to note that all three of the $60^{\circ} \mathrm{C}$ samples exhibited a large deposit of $\mathrm{Zn}$ at the center of the filter. A large island deposit was never observed for the $200^{\circ} \mathrm{C}$ samples, but was noted for one of the $120^{\circ} \mathrm{C}$ samples. The typical appearance of the filters in the as deposited condition is shown in Figure 3. The deposit island is indicated by the arrow for the $60^{\circ} \mathrm{C}$ sample. The bright areas on the samples are surface variations due to localized burnishing of the sample.

Figures 5 and 6 show the typical deposit morphology and chemical spectra for the 60 and $200^{\circ} \mathrm{C}$ filter temperatures, respectively. In both Figs. 5 and 6 the zinc particles appear like intertwined strings, referred to as lacy; they are not solid particles or individual whiskers. The apparent difference in composition is most likely caused by beam not impinging directly on the particle or by the beam having a larger diameter than the particle. Thus, detecting the presence of elements common to stainless steel is not uncommon for this type of analysis. In Fig. 6, the beam most likely was fully contained on the particle.

Figures 7, 8 and 9 show the SEM images for the 60,120 , and $200^{\circ} \mathrm{C}$ filter temperatures, respectively. In addition, the filter condition / deposit morphology near the edge, middle, and center of the coupon are shown. Figures 10-13 show a region of interest for the edge, middle, center, and bottom, the area from which the adhesion test was taken, and the associated X-ray dot map for zinc for the three temperatures. The bottom area examination was used to show that the adhesion test removed the zinc deposit from the surface of the filters and did not remove any of the well bonded material.

In Fig. 7, the deposit on the filter heated to $60^{\circ} \mathrm{C}$ exhibits two morphologies. The first is the lacy morphology and the second is plate-like. The amount of the plate-like deposit increases as the sample is traversed from the edge to the center. This increase in plate like deposit is consistent with the macrophotographs that show a near solid deposit at the center. The near solid zinc deposit is further substantiated in Fig. 12 for the $60^{\circ} \mathrm{C}$ center X-ray dot map. 
In Fig. 8, the deposit from the $120^{\circ} \mathrm{C}$ filter exhibits primarily a lacy morphology with varying filament thicknesses. The zinc is fairly evenly distributed as these lacy deposits. The distribution of the zinc can be also seen from the X-ray dot maps. From these four images, there is some qualitative indication that there may be a slightly higher zinc concentration towards the center, but this could also be solely due to the somewhat random areas that were examined.

In Fig. 9, the deposit from the $200^{\circ} \mathrm{C}$ filter can be seen. This sample exhibits a mixture of both lacy with a few areas of plate-like deposits. The X-ray dot maps indicate that the zinc is also fairly well distributed with more zinc concentrated near the center based on the X-ray dot maps. As was the case for the other filter temperatures, the zinc was not removed during the adhesion test for this deposition condition.

\section{Discussion}

The results from mass change for the deposition conditions suggest that the lowest temperature filter was better for trapping zinc vapors the higher temperatures. The mass increase for the $60^{\circ} \mathrm{C}$ filter was on average the highest, but the standard deviation was also high. The statistical analysis suggests that all three filters perform about the same, i.e., 2-3 mg / filter. The reason for the scatter and the apparent differences in individual deposit amounts and efficiencies was not determined.

Based on the simple tape adhesion test, differences in adhesion strength were observed between the different sample temperatures. The zinc was measurably less adherent for the $60^{\circ} \mathrm{C}$ filters than the either the 120 or $200^{\circ} \mathrm{C}$ filters. The $60^{\circ} \mathrm{C}$ samples lost a little over $0.5 \mathrm{mg}$ on all of the tests while the $200^{\circ} \mathrm{C}$ samples lost only $0.2-0.3 \mathrm{mg}$ each. This difference can likely be attributed to the large island of $\mathrm{Zn}$ that deposited in the center of the $60^{\circ} \mathrm{C}$ sample and did not bond to the filter or form the deposit within a filter pore. This central deposit exhibited a plate like structure rather than a lacy structure. The $120^{\circ} \mathrm{C}$ sample also exhibited a mixed deposit morphology with both lacy and plate like structures being observed on the sample, while the $200^{\circ} \mathrm{C}$ filter temperature exhibited a lacy structure exclusively.

Based on the literature, the lacy structure is consistent with a higher deposition temperature that would lead to a more adherent deposit. It was also intimated that filter temperatures in excess of 0.5 of the homologous temperature should be used $(6 \& 9)$. These conditions were met for the 120 and $200^{\circ} \mathrm{C}$ filter temperatures. The adhesion test indicates that less material was removed from the 120 and $200^{\circ} \mathrm{C}$ samples than from the $60^{\circ} \mathrm{C}$ samples and the deposit did not form the lacy structure as consistently.

In addition to trapping the zinc vapors, at which all three test temperatures were effective, it is also desirable to contain the zinc deposits on or in the filter media. The adhesion test provides an indication of transferable contamination. Thus, based on the results of the adhesion test and the deposit morphology, it appears that both 120 and $200^{\circ} \mathrm{C}$ filter temperatures perform better than $60^{\circ} \mathrm{C}$. Future operations for the TEF should continue to use the $20 \mu \mathrm{m}$ filters heated to at least $60^{\circ} \mathrm{C}$. Increasing the filter temperature to between 120 and $200^{\circ} \mathrm{C}$ may produce a more adherent deposit. The compromise is that the higher temperature requires additional instrumentation and equipment in the glovebox while the $60^{\circ} \mathrm{C}$ is a common heat trace temperature. The need to simply entrap the zinc vapor on the filter media must be balanced by the potential spread of contaminant particulate due to removal of the ${ }^{65} \mathrm{Zn}$ by abrasion during maintenance. 


\section{Conclusions}

The filter temperature affects both the deposit morphology and the deposit adhesion. The deposit is more readily removed when it is applied at low temperatures than when it is applied at higher temperatures.

Based on the morphology and adhesion testing, the zinc filters should be heated to temperatures greater than $60^{\circ} \mathrm{C}$. Both the 120 and $200^{\circ} \mathrm{C}$ filter temperatures produce a more adherent zinc deposit than $60^{\circ} \mathrm{C}$. The need to simply trap the zinc vapors needs to be balanced against the need to trap and better contain the zinc deposit. The homologous temperature in excess of 0.5 appears necessary to achieve better adhesion to and within the filter.

It is expected that a similar approach should be used for the containment of ${ }^{109} \mathrm{Cd}$, i.e., the filters would be held at a homologous temperature consistent with $0.5 \mathrm{~T}_{\mathrm{M}}$ or higher for $\mathrm{Cd}$, which is $24^{\circ} \mathrm{C}$ or higher.

\section{References}

1. SRNL-L4400-2010-00003, Zinc Mitigation Interim Report -- Effect of Pore Size, P. Korinko, Dec. 17,2010

2. SRNL-L7100-2010-00019, ${ }^{65} \mathrm{Zn}$ Trapping and Containment Optimization, P. Korinko, 5/2010

3. TTP-1-3003, White paper to Address Contamination Issues in TEF, E.F. Love, 2008.

4. SRNL-L7100-2008-00001, Analysis of TEF Pipe with ${ }^{65} \mathrm{Zn}$ Contamination P. Korinko, M. Tosten, Z. Nelson, 9/2008

5. SRNL-L7100-2010-00008, Examination of TEF Filters for ${ }^{65} \mathrm{Zn}$ Trapping, Paul Korinko, Michael Tosten, Zane Nelson, 2/2010

6. SRNL-LM200-2009-00013, Recommendations for TEF to Minimize Further Contamination of ${ }^{65} \mathrm{Zn}$, Paul Korinko, Robert Malstrom, and Andrew Duncan, 4/2009

7. SRNL-L7100-2010-00034, Examination of New Filter Media used for Zn Coalescing Filters, Paul Korinko, 8/2010

8. $\quad$ SRNL-L7100-2010-00039, Zinc Deposition R\&D Direction, P. Korinko, 11/2010.

9. B.A. Movchan and A.V. Demshishin, "Study of the Structure and Properties of Thick Vacuum Condensates of Nickel, Titanium, Tungsten, Aluminum Oxide and Zirconium Dioxide", Fiz. Metal. Metaloved., 28, No. 4, 653-660, 1969. 
Table 1. Test Condition and results

\begin{tabular}{|l|l|l|l|l|l|l|l|}
\hline Test ID & Date & Vessel T $\left({ }^{\circ} \mathrm{C}\right)$ & Filter A $\left({ }^{\circ} \mathrm{C}\right)$ & Filter B $\left({ }^{\circ} \mathrm{C}\right)$ & $\Delta$ mass $(\mathrm{mg})$ & $\Delta$ loss ad. $(\mathrm{mg})$ & Comments \\
\hline $60-1$ & $1-26$ & 340 & 55 & 52 & 3.8 & 0.8 & Deposit at center \\
\hline $60-3$ & $2-10$ & 380 & 57 & 50 & 2.1 & 0.5 & Deposit at center \\
\hline $60-4$ & $3-3$ & 384 & 56 & 50 & 3.7 & 0.5 & $\begin{array}{l}\text { Deposit at center } / \\
\text { Ash on housing }\end{array}$ \\
\hline $120-2$ & $2-28$ & 340 & 116 & 96 & 1.6 & 0.1 & Ash on housing \\
\hline $120-4$ & $3-1$ & 384 & 116 & 97 & 2.9 & 0.2 & \\
\hline $200-1$ & $1-26$ & 340 & 196 & 160 & 2.6 & 0.3 & \\
\hline $200-2$ & $2-8$ & 340 & 200 & 165 & $5.5^{*}$ & 0.3 & Ash on housing \\
\hline $200-4$ & $2-28$ & 384 & 199 & 149 & 2.4 & 0.2 & Ash on housing \\
\hline
\end{tabular}

Notes: "A" refers to thermocouple mounted Above the filter and "B" to the one below. "ad" refers to mass loss during tape adhesion test. *sample was subjected to a double exposure at $400^{\circ} \mathrm{C}$. Missing Test ID are due to poorly executed experiments. The thermocouples were reset on Feb 10, 2011 which resulted in changes in measured vessel temperatures.

Table 2. Test temperatures and homologous temperature $\left(T(K) / T_{\text {melt }}(K)\right)$, where $T_{\text {melt }}=419.5^{\circ} \mathrm{C}$ or $692.5 K$.

\begin{tabular}{|r|r|r|r|}
\hline Temp & $\begin{array}{l}\text { Homologous } \\
\text { Temp }\end{array}$ & Average & $\begin{array}{l}\text { Std } \\
\text { Dev }\end{array}$ \\
\hline 25 & 0.43 & & \\
\hline 60 & 0.48 & 3.20 & 0.95 \\
\hline 120 & 0.57 & 2.25 & 0.92 \\
\hline 200 & 0.68 & 2.50 & 0.14 \\
\hline
\end{tabular}




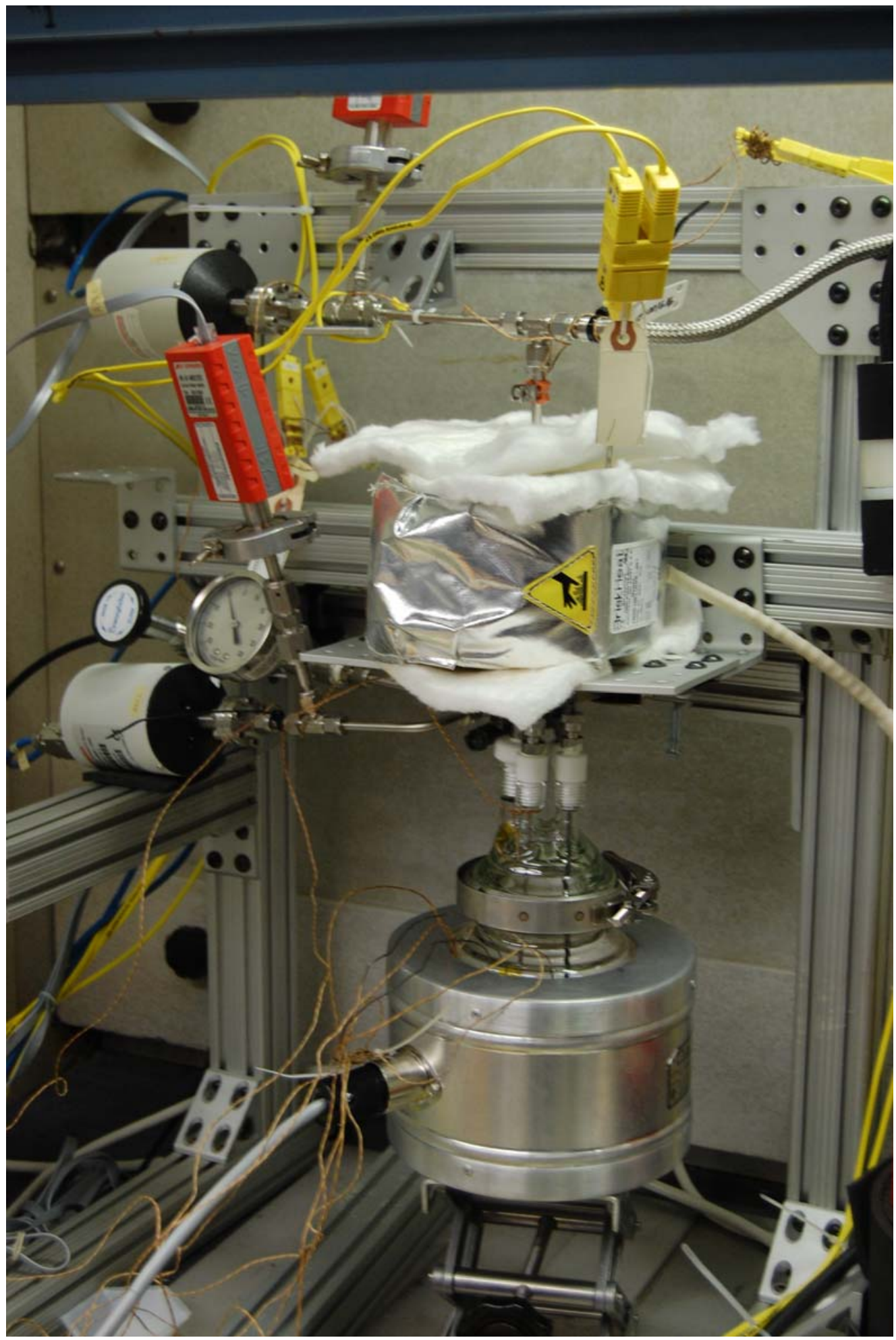

Figure 1. Photographs of zinc TVD apparatus used for this study. 

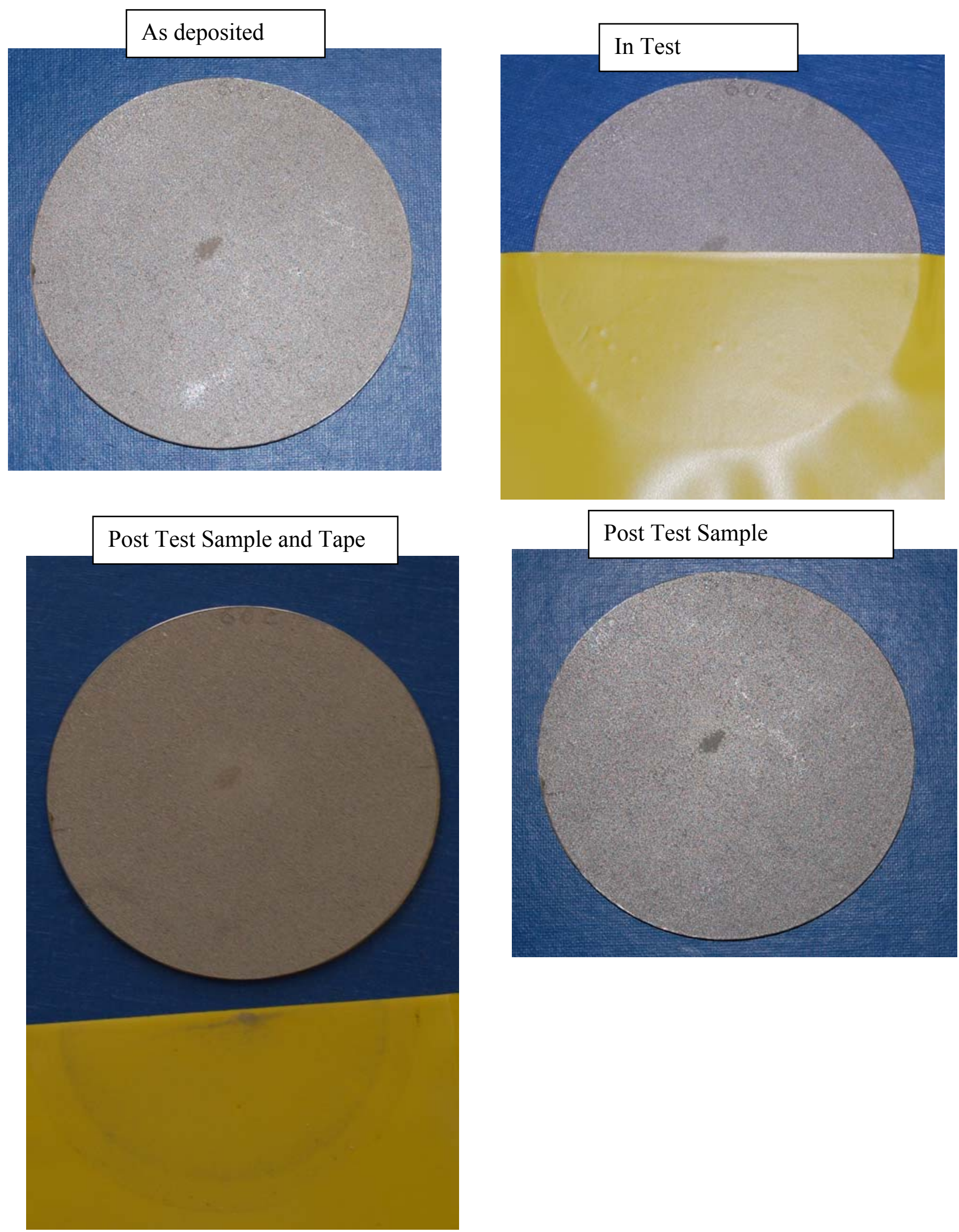

Figure 2. Pictorial description of the Adhesion Test for a $60^{\circ} \mathrm{C}$ filter test. 
20 um Filter 120C/4 hr $400 \mathrm{C} / 3 \mathrm{hr}$ Vessel run 4

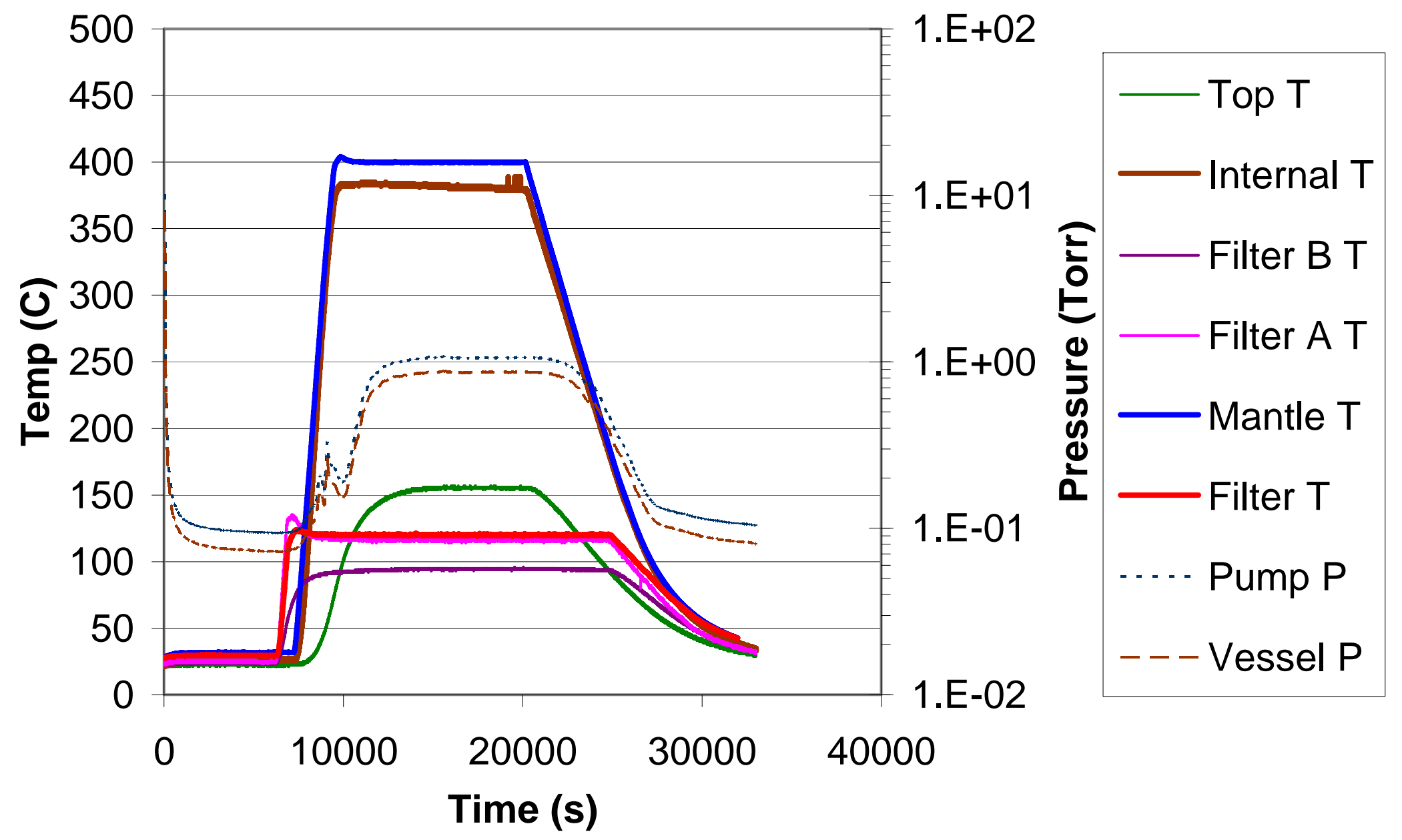

Figure 3. Typical thermal data for the vessel and filter. These data are for a sample exposed at a nominal $400^{\circ} \mathrm{C}$ vessel temperature and a $120^{\circ} \mathrm{C}$ filter temperature. 


\section{S RNL-STI-2011-00348}
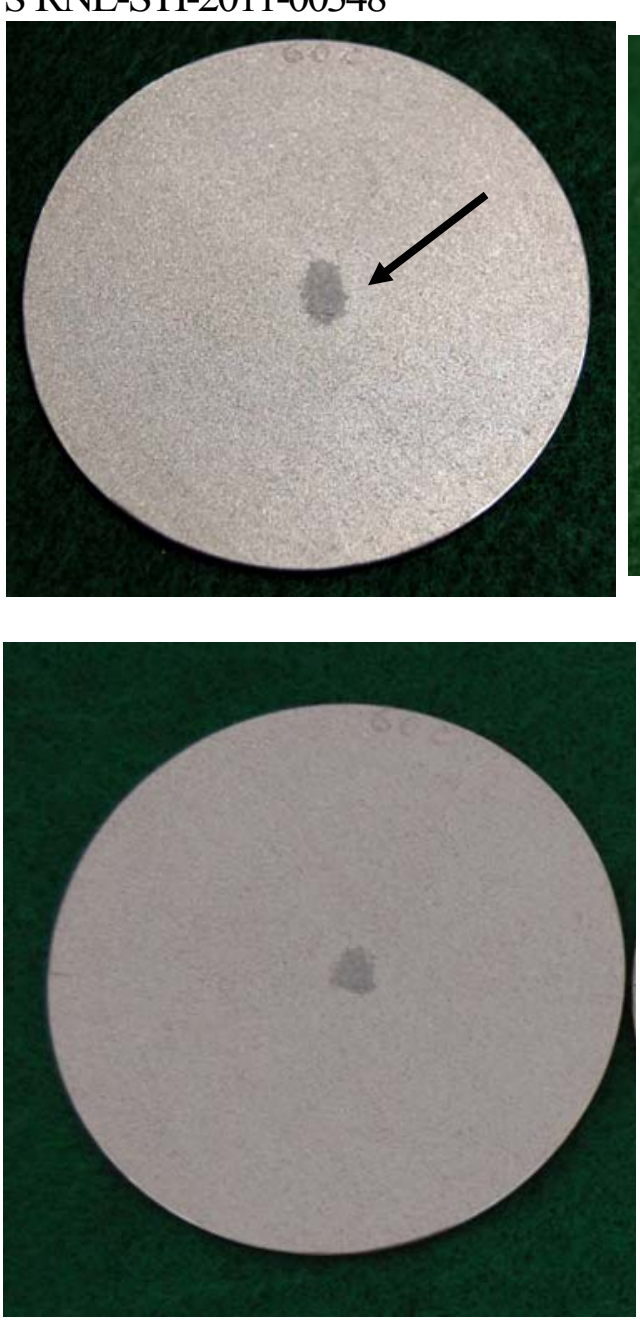

$60^{\circ} \mathrm{C}$

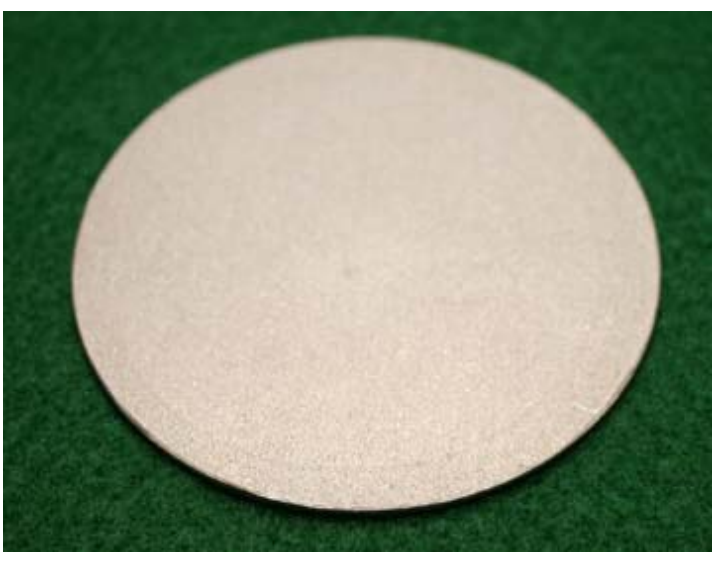

page 10
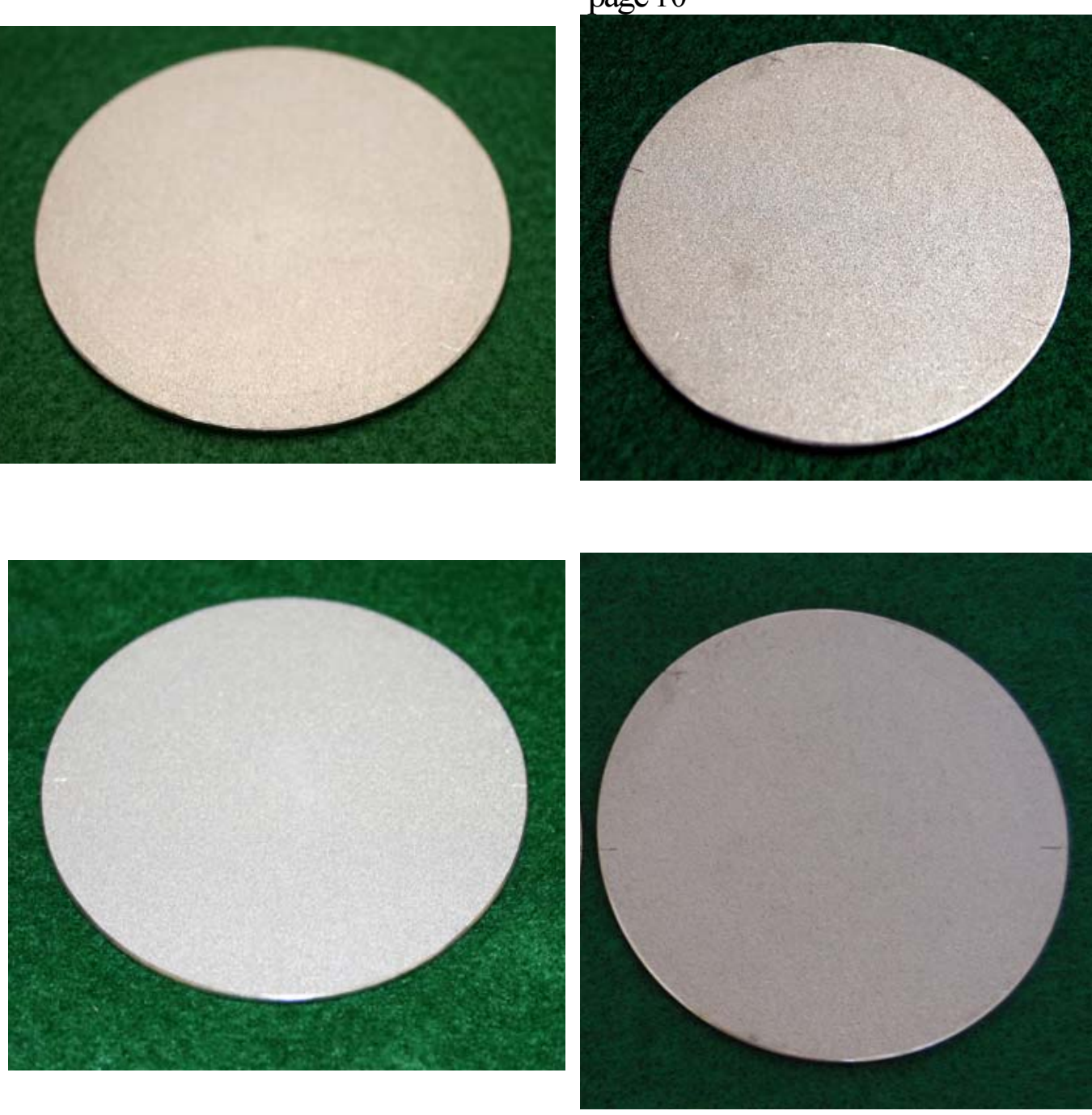

$120^{\circ} \mathrm{C}$

$200^{\circ} \mathrm{C}$

Figure 4. Deposit appearance for filters exposed at $60^{\circ} \mathrm{C}, 120^{\circ} \mathrm{C}$, and $200^{\circ} \mathrm{C}$ in the as deposited (upper) and adhesion tested (lower) conditions. Note: about half the deposit was removed from the $60^{\circ} \mathrm{C}$ sample. This result was consistent across all three $60^{\circ} \mathrm{C}$ filter tests. 

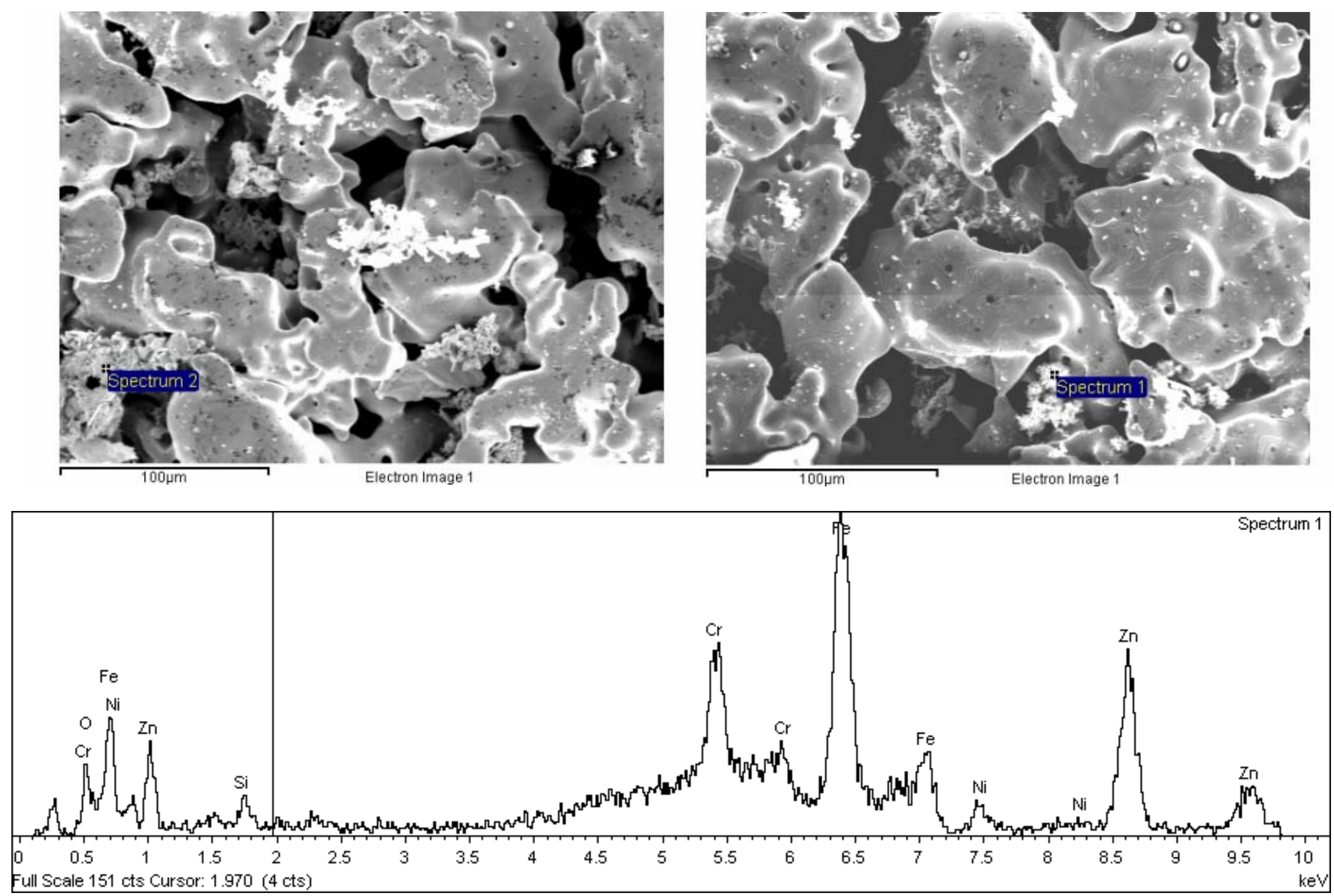

Figure 5. Particle and nominal chemistry for the filter exposed at $60^{\circ} \mathrm{C}$. The beam sampling volume included some of the stainless steel filter media. 

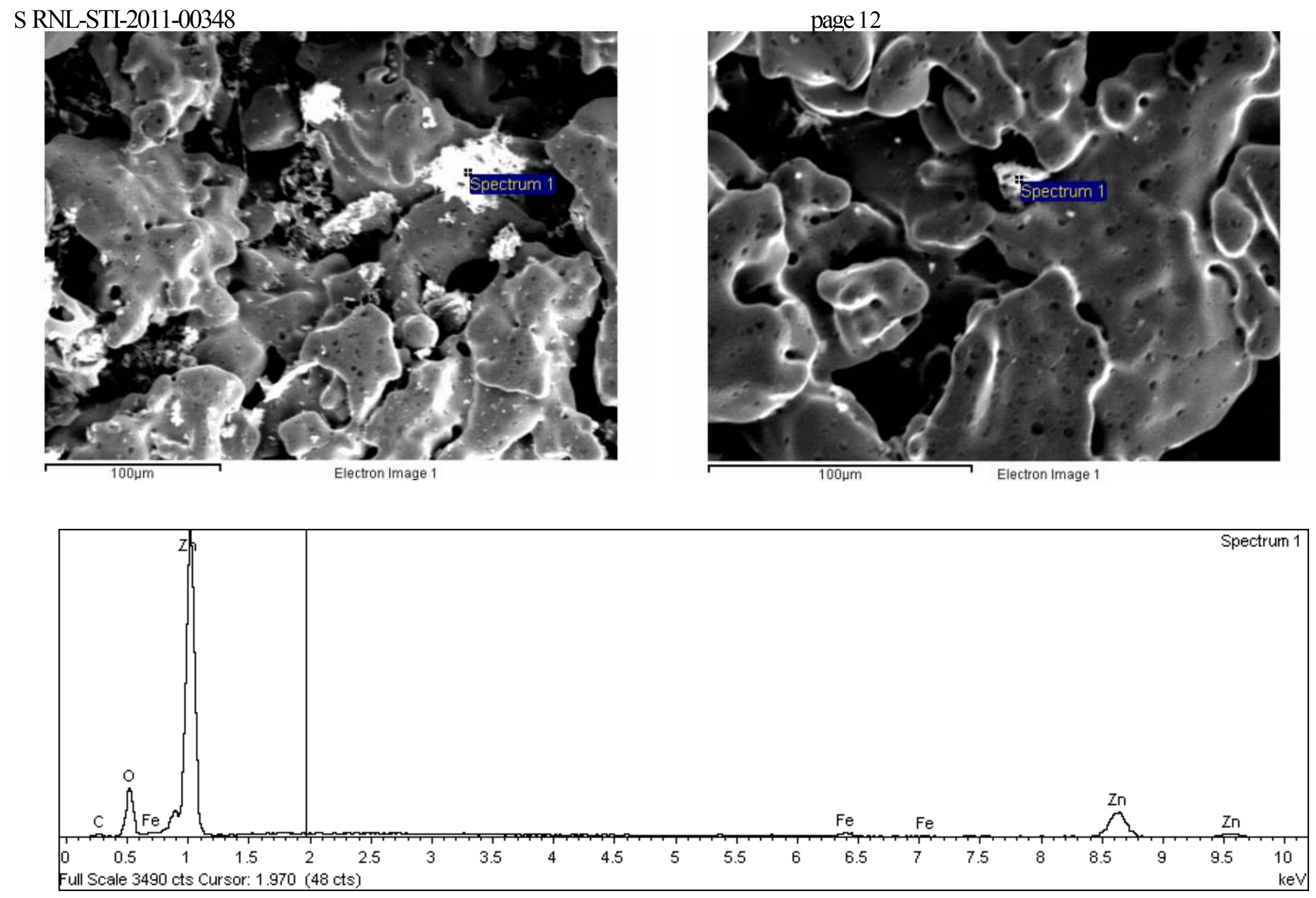

Figure 6. Typical deposit found on a filter exposed at $200^{\circ} \mathrm{C}$. EXDA indicates nearly pure zinc. 

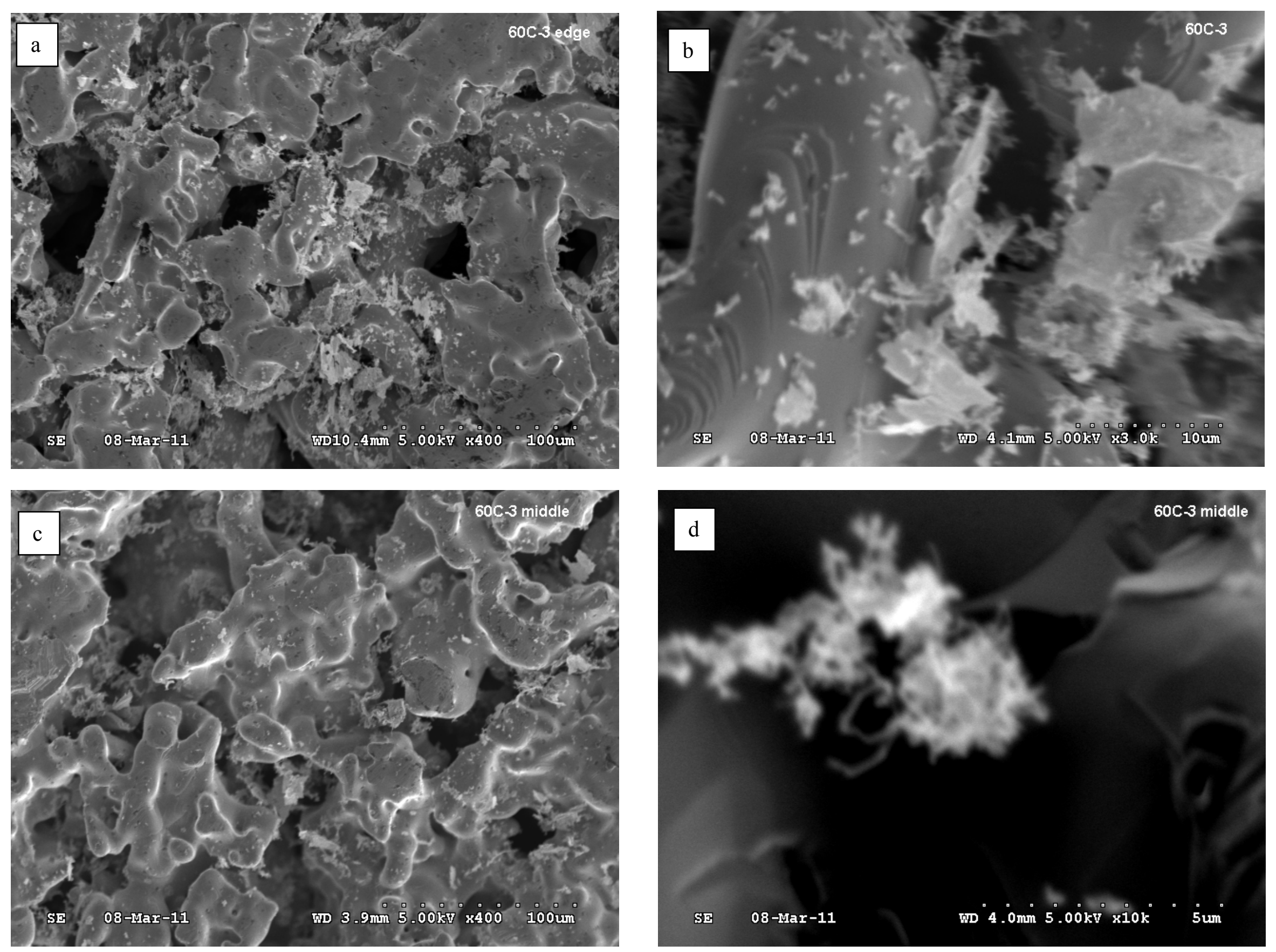

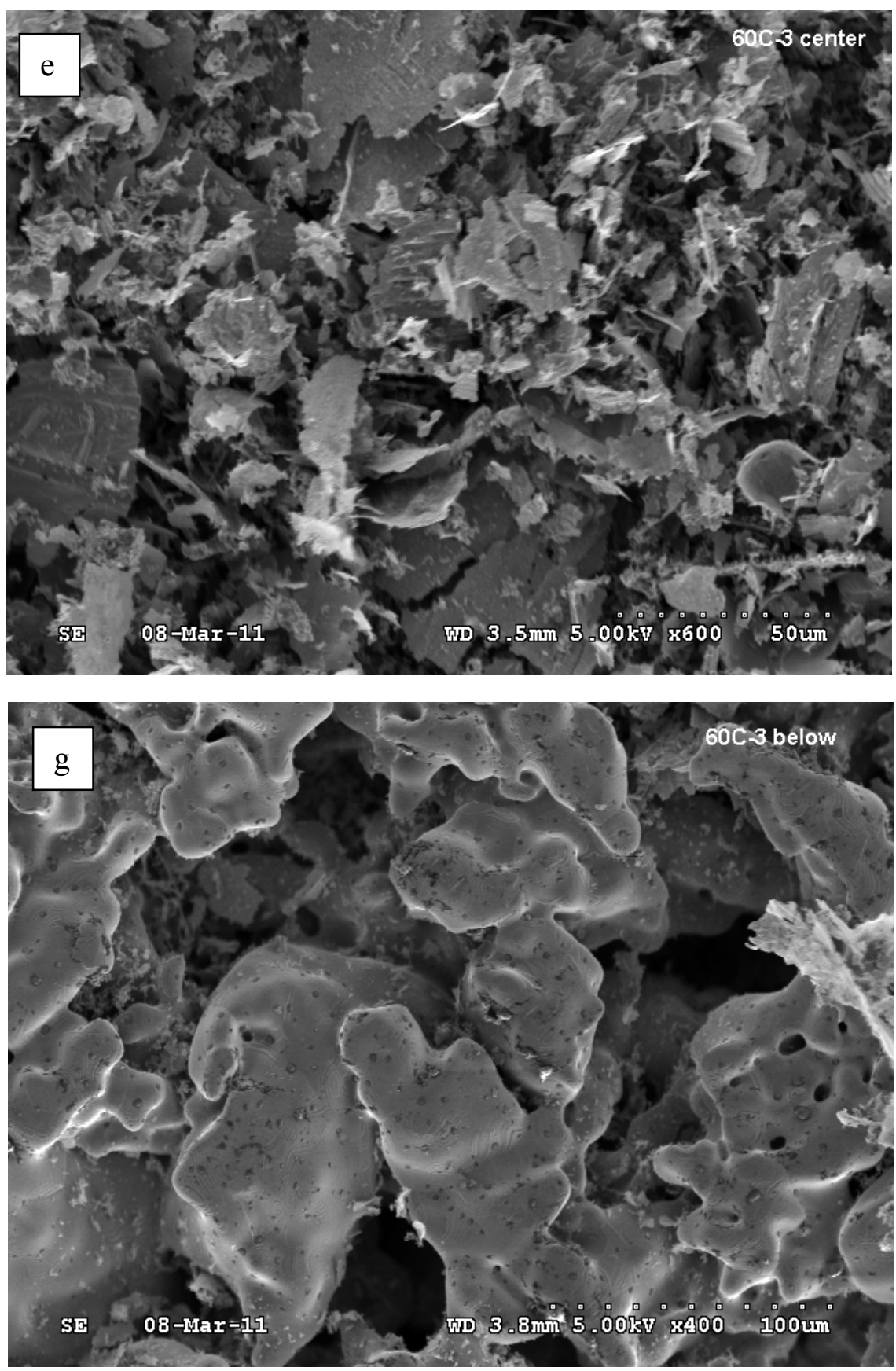

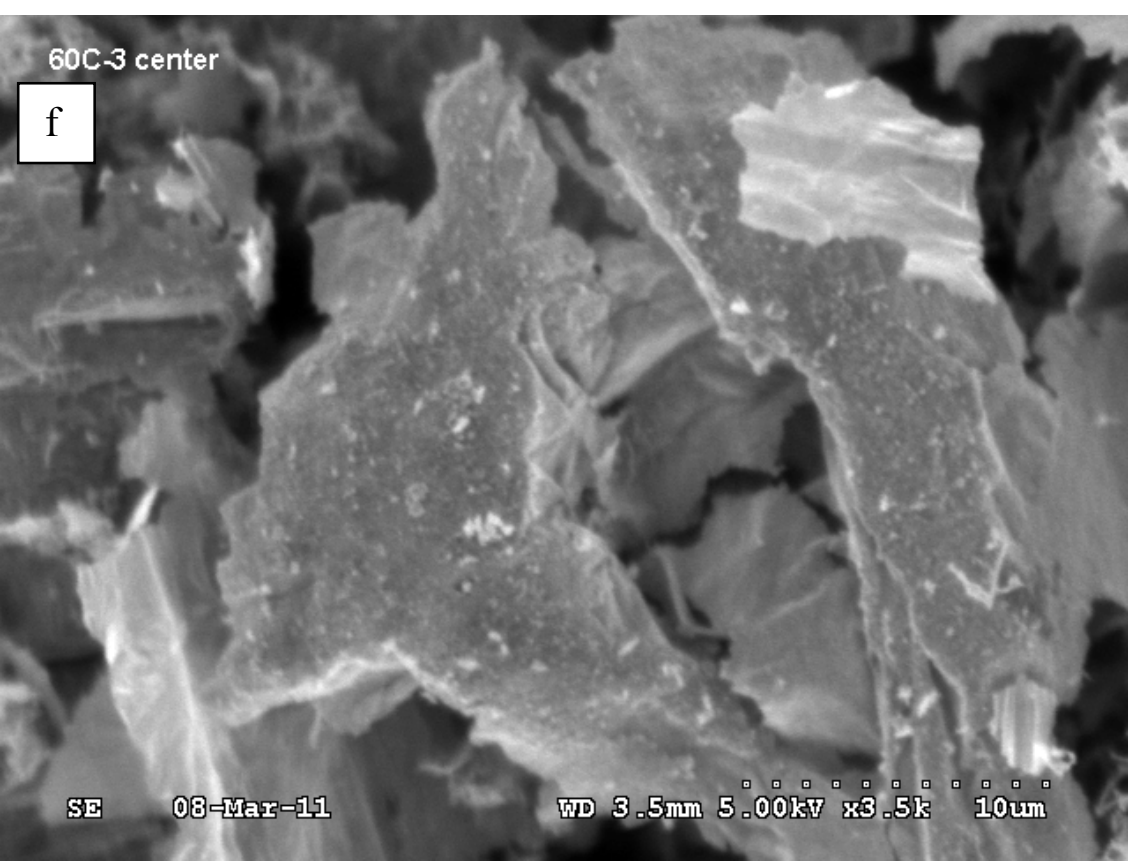

Figure 7. SEM images from the $60^{\circ} \mathrm{C}$ filter -4 (a) edge low magnification (b) edge high magnification showing flake like structure (c) middle section between edge and center at low magnification (d) higher magnification of (c) (e) center at low magnification and (f) center at high magnification showing flake-like deposit (g) area from the adhesion test demonstrating that surface deposits were removed but not subsurface. 


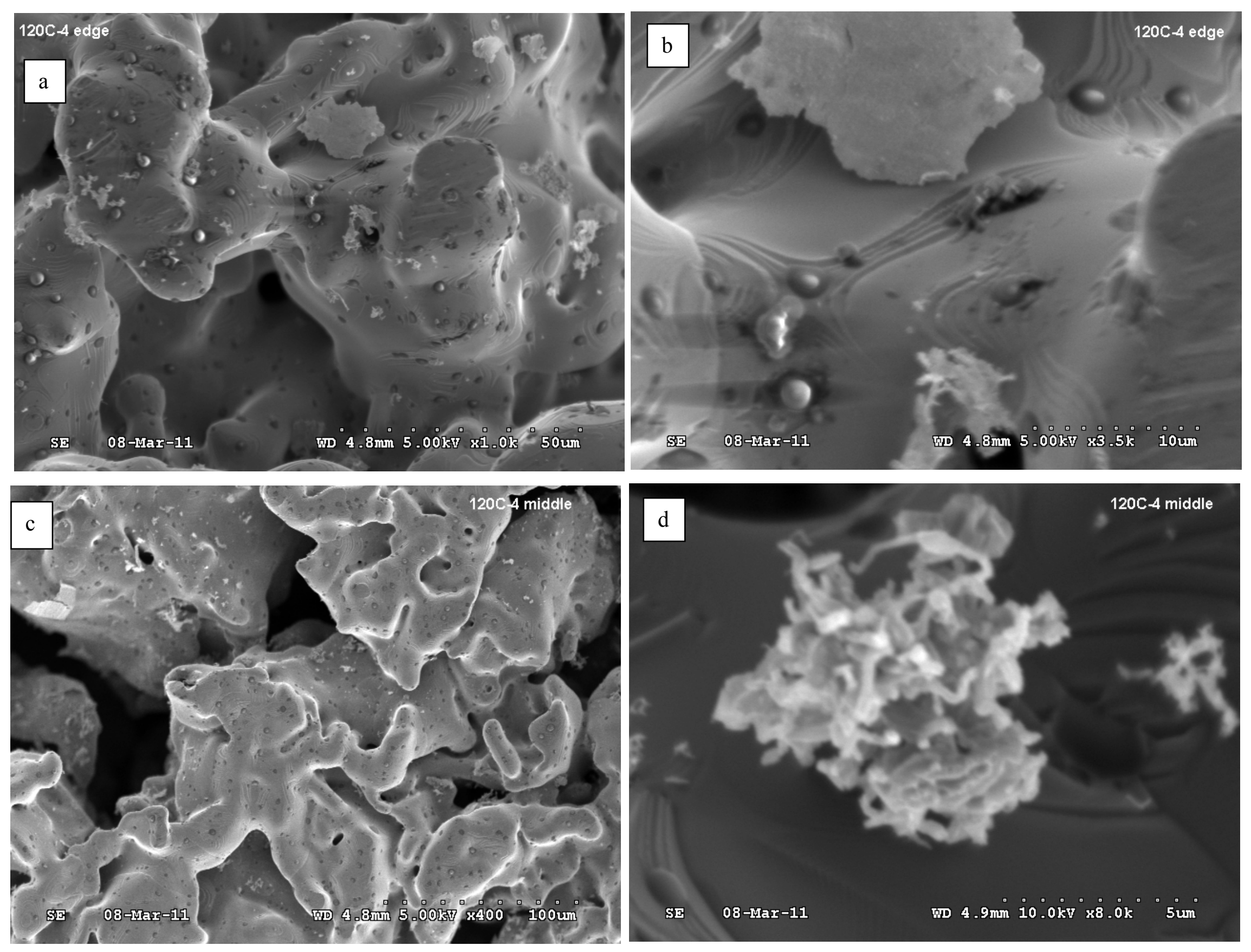



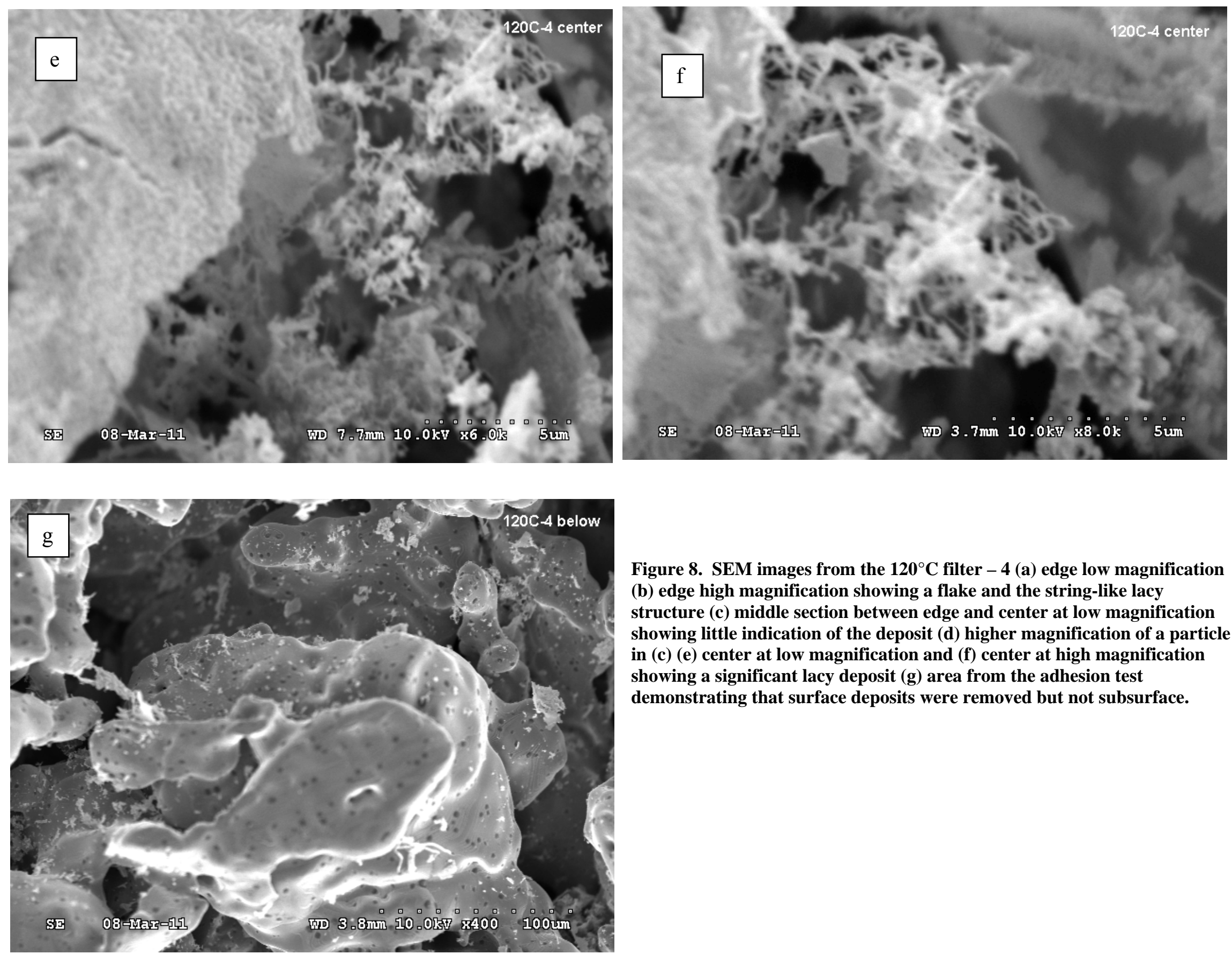

Figure 8. SEM images from the $120^{\circ} \mathrm{C}$ filter -4 (a) edge low magnification (b) edge high magnification showing a flake and the string-like lacy structure (c) middle section between edge and center at low magnification showing little indication of the deposit (d) higher magnification of a particle in (c) (e) center at low magnification and (f) center at high magnification showing a significant lacy deposit (g) area from the adhesion test demonstrating that surface deposits were removed but not subsurface. 

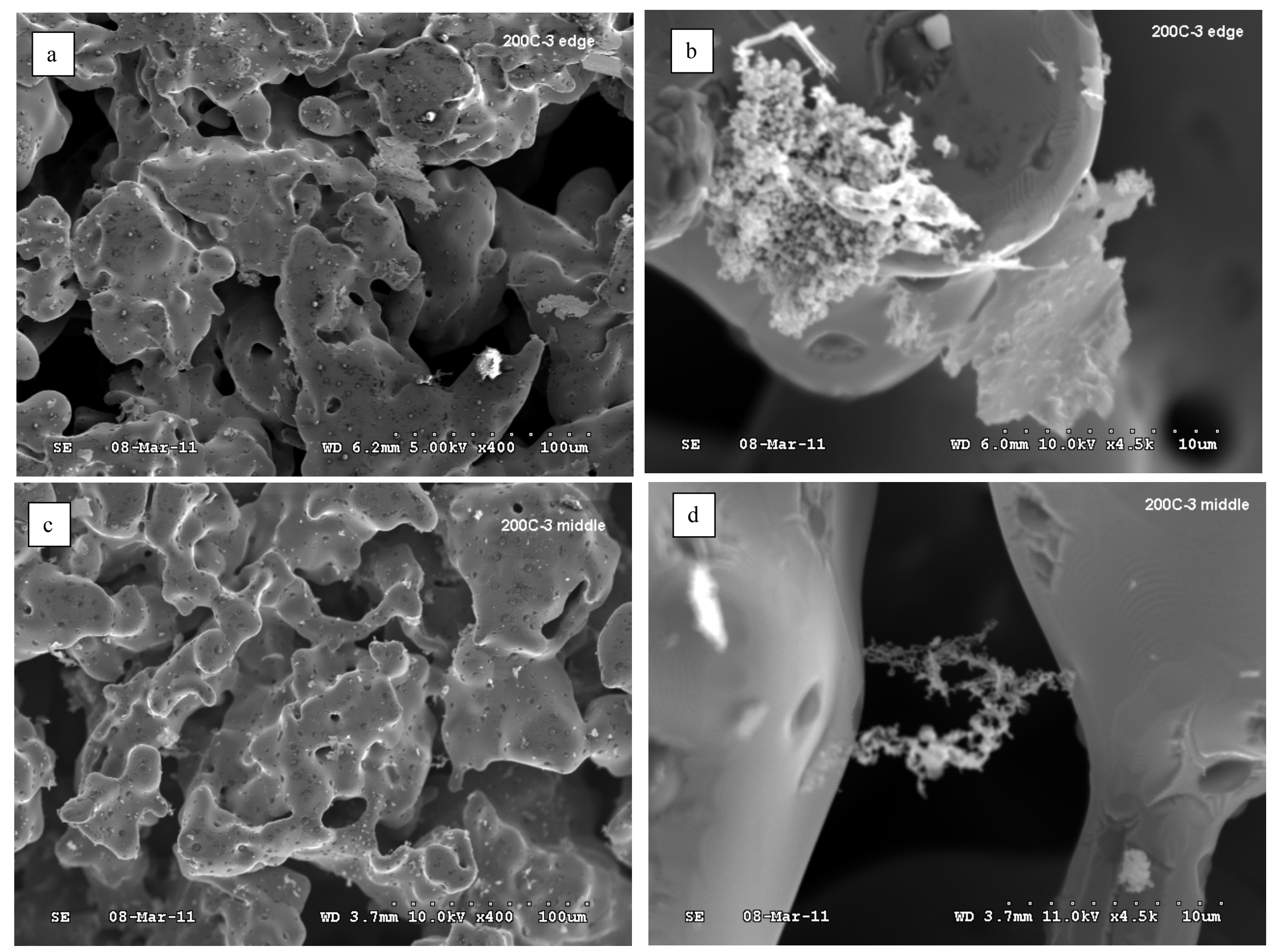

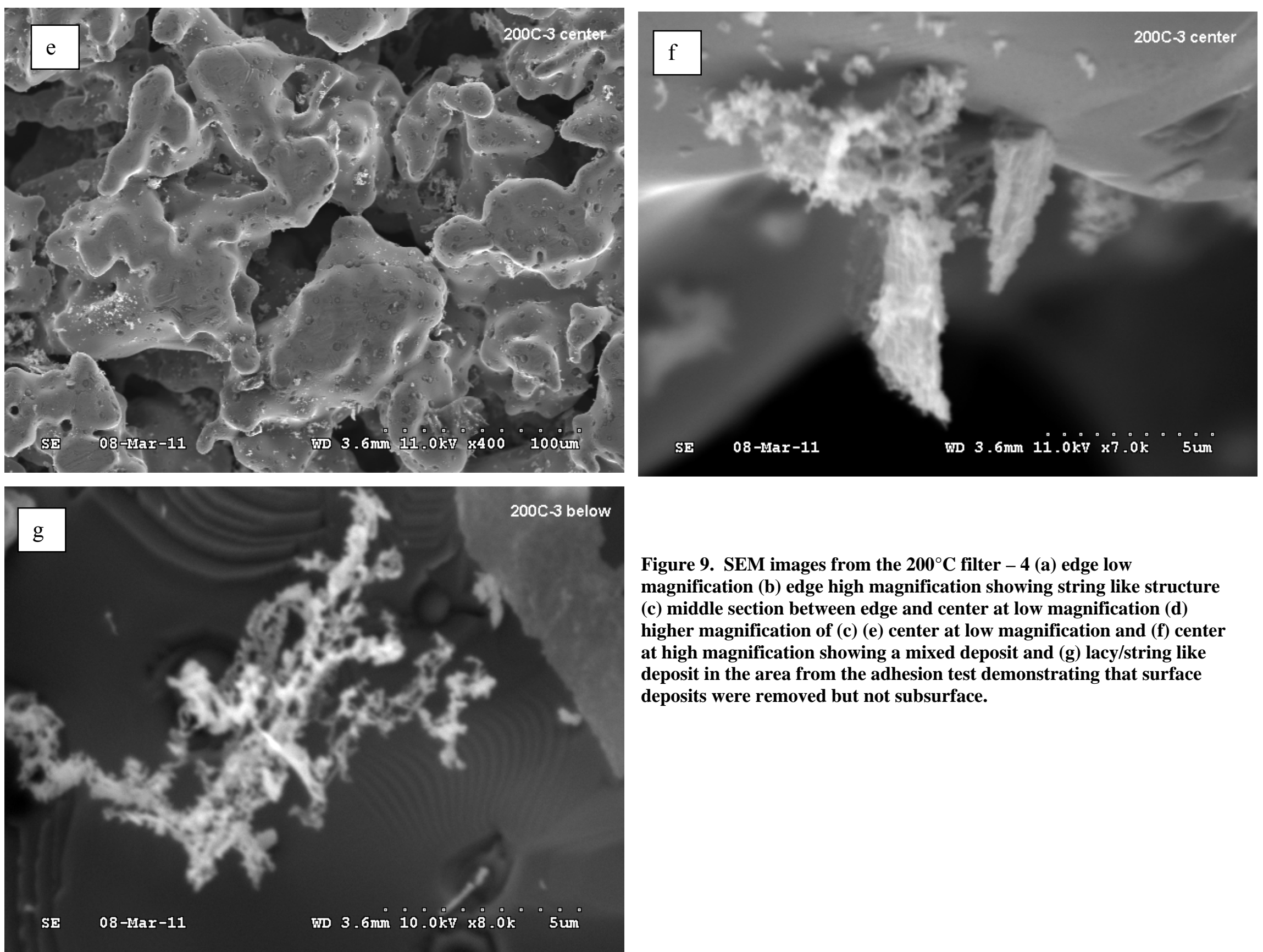

Figure 9. SEM images from the $200^{\circ} \mathrm{C}$ filter -4 (a) edge low magnification (b) edge high magnification showing string like structure (c) middle section between edge and center at low magnification (d) higher magnification of (c) (e) center at low magnification and (f) center at high magnification showing a mixed deposit and (g) lacy/string like deposit in the area from the adhesion test demonstrating that surface deposits were removed but not subsurface. 

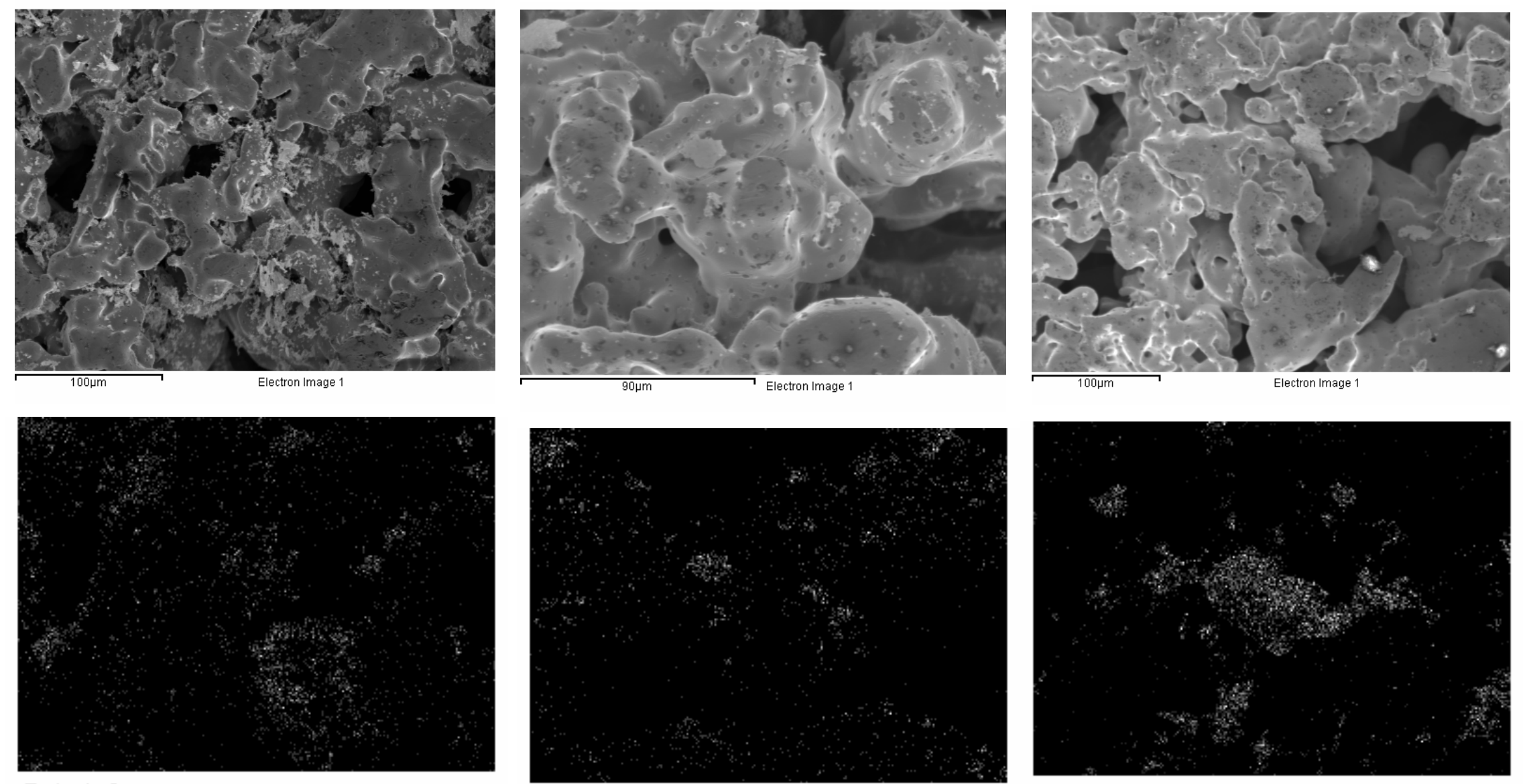

Zn La1_2

Zn La1_2

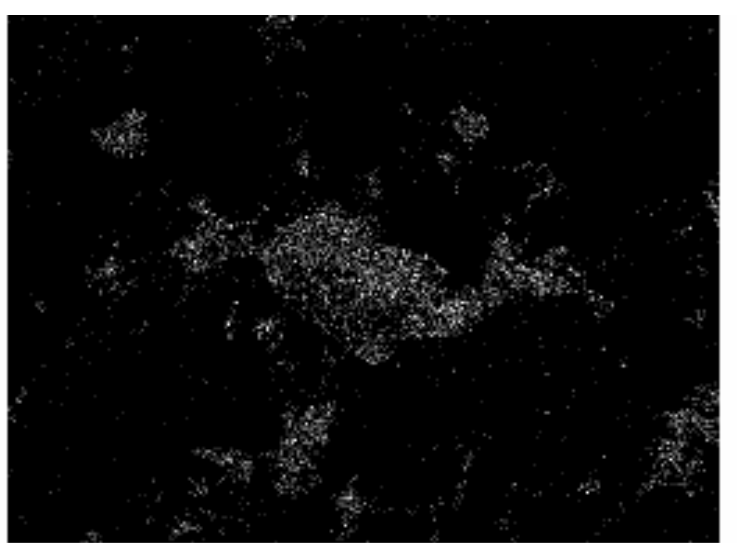

$60 \mathrm{C}$ Edge

120C Edge

200C Edge

Figure 10. Typical morphology and $x$-ray dot maps from the edge sample showing the dispersion of zinc in the sample. 

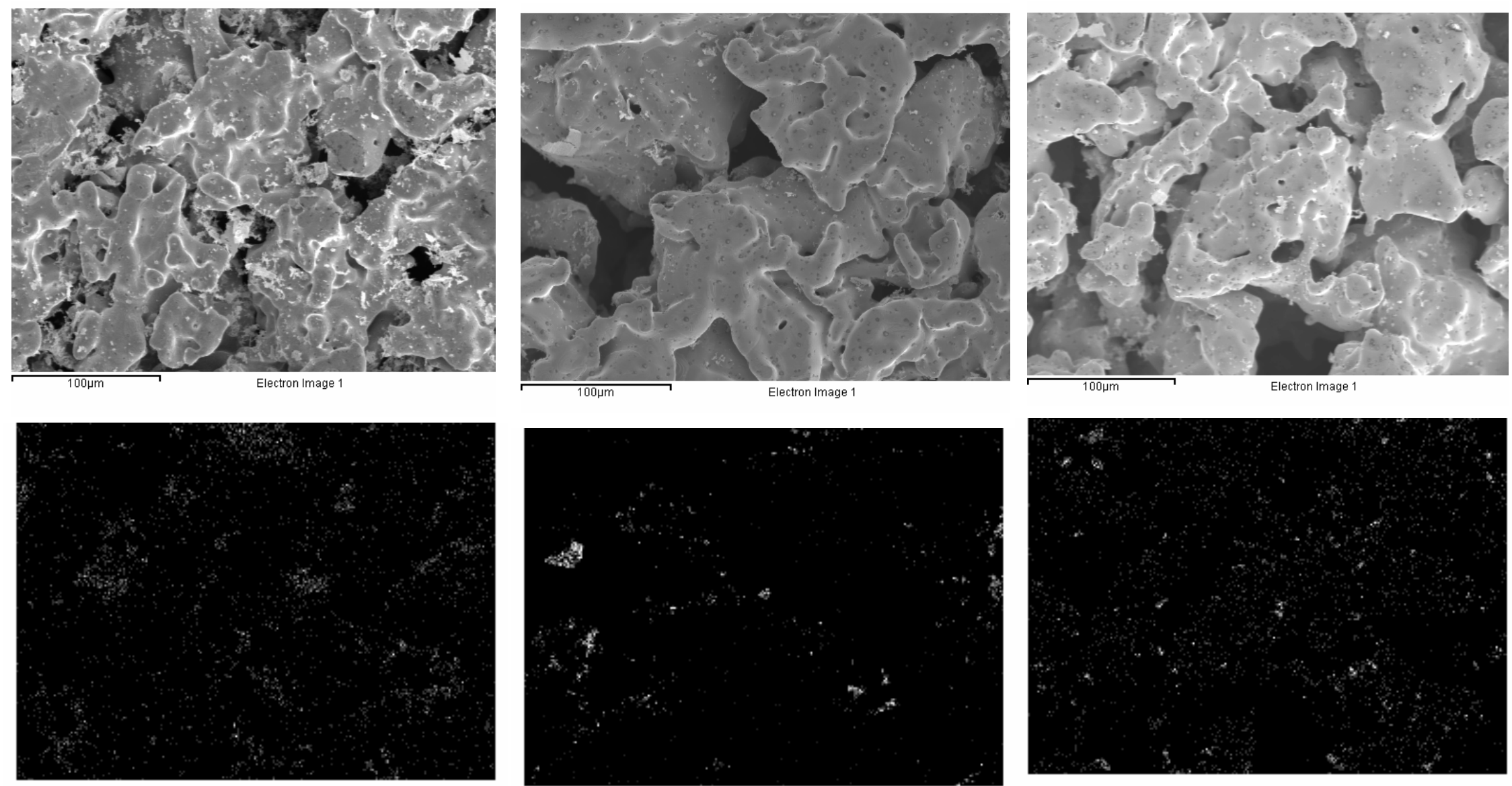

Zn La1_2

60C Middle

Zn La1_2

120C Middle

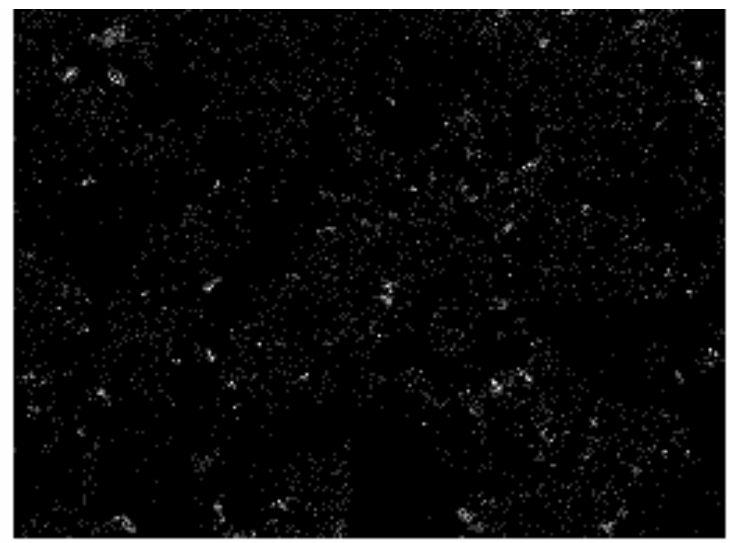

Zn La1_2

200C Middle

Figure 11. Morphology and X-ray dot maps from the middle of the sample showing the zinc dispersion and location of particles. 

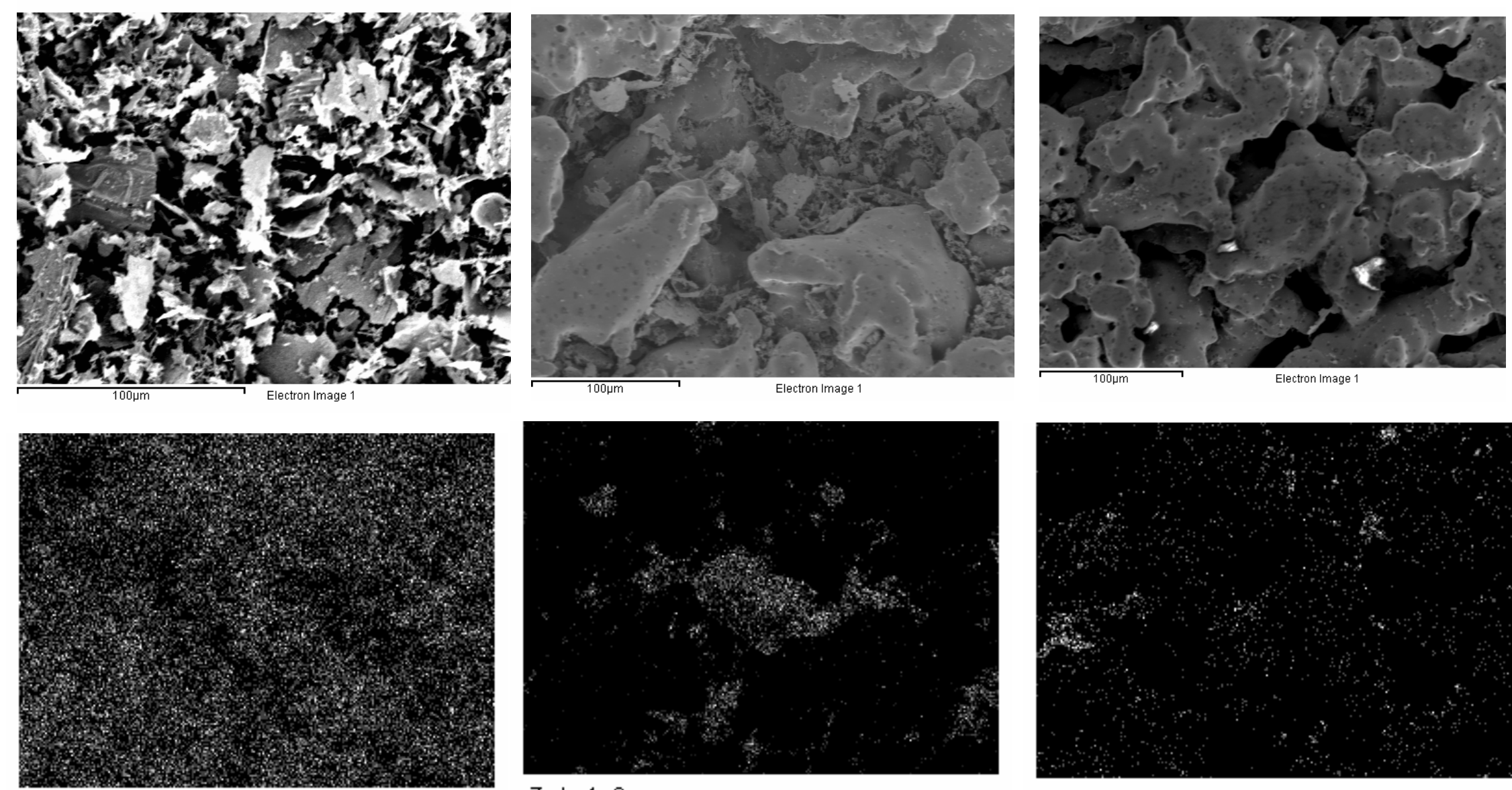

Zn La1_2

Zn La1_2

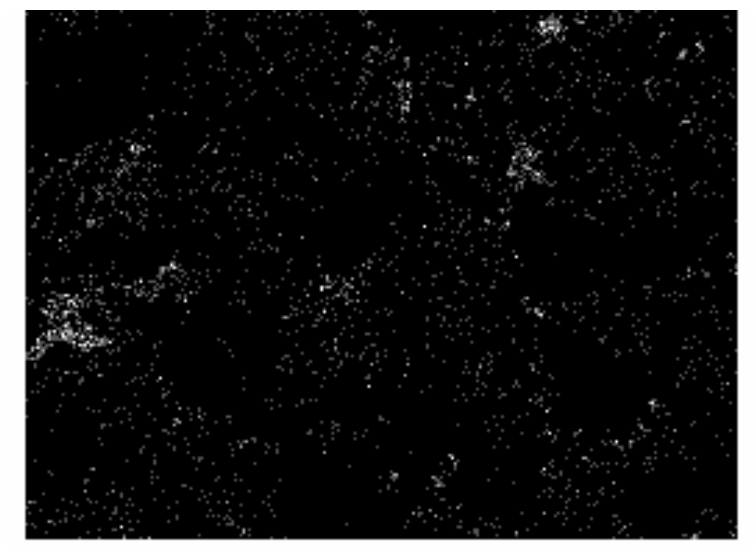

60C Center

120C Center

200C Center

Figure 12. Morphology and X-ray dot maps from the middle of the sample showing the zinc dispersion and location of particles. 

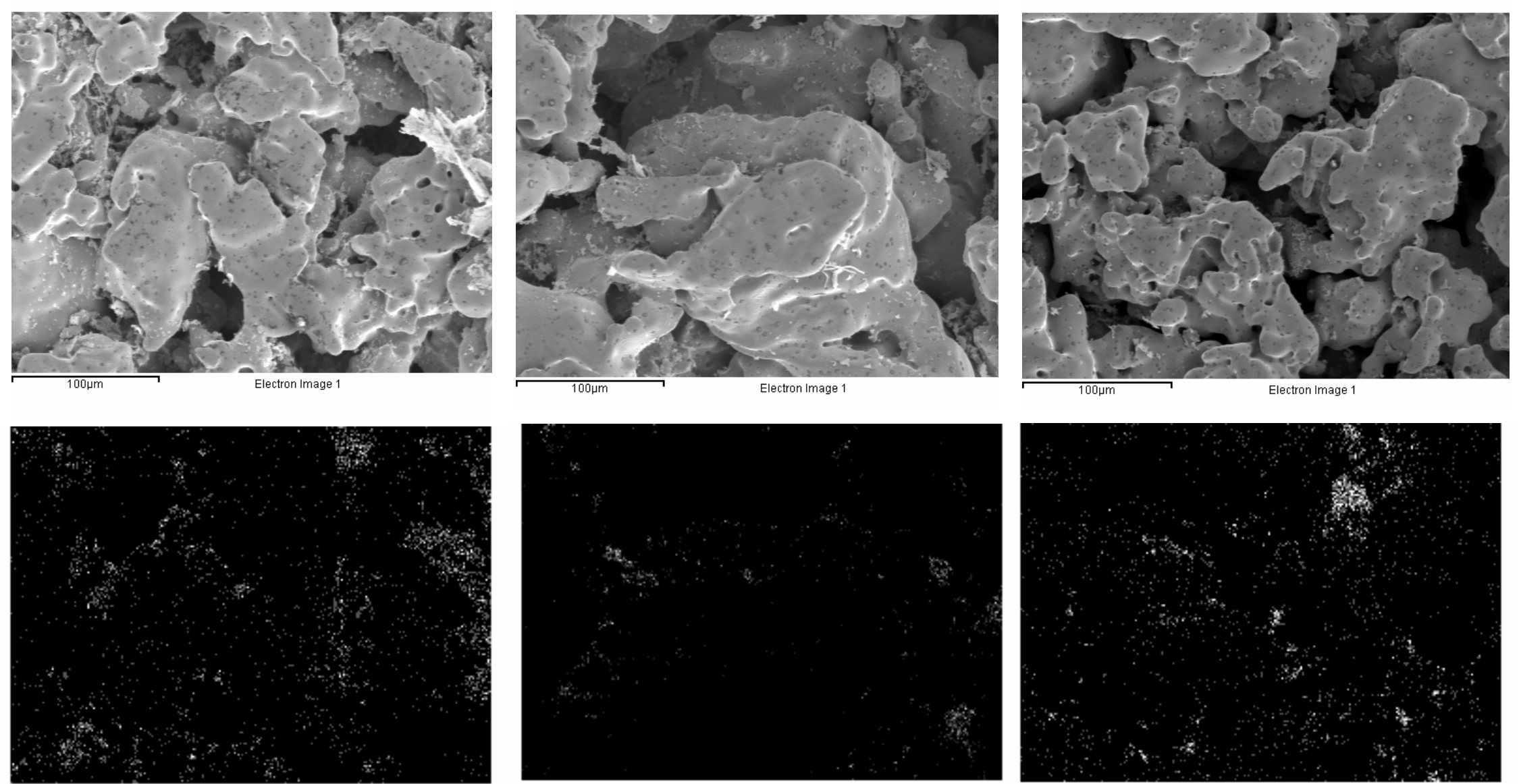

Zn La1_2

Zn La1_2

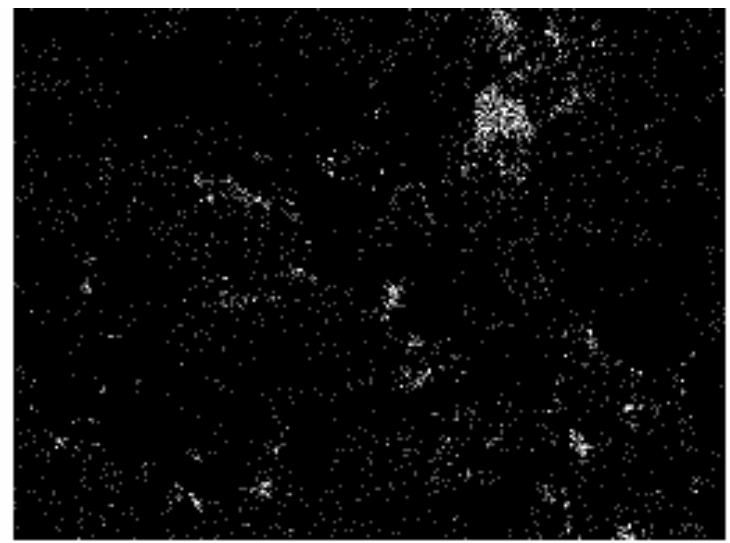

60C Below

120C Below

200C Below

Figure 13. Morphology and X-ray dot maps from the area below the tape adhesion test near the center of the sample showing the zinc dispersion and location of particles. 